University of Warwick institutional repository: http://go.warwick.ac.uk/wrap This paper is made available online in accordance with publisher policies. Please scroll down to view the document itself. Please refer to the repository record for this item and our policy information available from the repository home page for further information.

To see the final version of this paper please visit the publisher's website. Access to the published version may require a subscription.

Author(s): Andrew Roberts

Article Title: Eyewitness Identification Evidence: Procedural Developments and the Ends of Adjudicative Accuracy

Year of publication: 2009

Link to published version: http://dx.doi.org/10.2202/1554-4567.1087

Publisher statement: None 


\section{International Commentary on Evidence}

Volume 6, Issue 2 2009 Article 3

EVIDENCE DURING THE TEN YEARS OF ICE

Eyewitness Identification Evidence:

Procedural Developments and the Ends of Adjudicative Accuracy

Andrew Roberts* 


\title{
Eyewitness Identification Evidence: Procedural Developments and the Ends of Adjudicative Accuracy
}

\author{
Andrew Roberts
}

\begin{abstract}
This article provides critical analysis of some of the more notable procedural developments relating to eyewitness identification evidence over the past decade.
\end{abstract}

KEYWORDS: eyewitness identification, procedural rights, adjudicative accuracy, evidential defficiencies 
This article considers some of the more notable developments that have occurred in the law relating to eyewitness identification evidence over the past decade. In that period there has been a move away from the use of traditional corporeal identification parades (line-ups) in favour of video identification procedures in England and Wales. In the United States, the National Institute of Justice has published guidelines for law enforcement officers concerning the pretrial procedures that ought to be used to obtain identification evidence from eyewitnesses. This precipitated the adoption in some jurisdictions in the US of novel identification procedures in which those appearing in the procedure are presented to the witness sequentially rather than simultaneously, as they are in traditional identification parades or lineups. In Australia, the Uniform Evidence Acts 1995 (Cth and NSW) establish an exclusionary rule in respect of visual identification evidence where no identification parade has been conducted. A number of Australian jurisdictions have subsequently considered adoption of the Uniform Evidence Acts, ${ }^{1}$ Victoria having recently introduced a Bill which will lead to enactment of the uniform legislation in that jurisdiction. ${ }^{2}$ In New Zealand, a similar exclusionary approach is set out in recently enacted codifying legislation. ${ }^{3}$

What follows is a necessarily selective evaluation of developments across various jurisdictions, rather than a comprehensive catalogue of procedural reform. The first section considers some of the normative principles that we might expect to shape the law relating to eyewitness identification evidence. I will argue that one of the principal objectives of this aspect of procedural law ought to be to mitigate, so far as possible, qualitative and quantitative deficiencies in the evidence presented to the tribunal of fact. ${ }^{4}$ These deficiencies are an inevitable feature of criminal trials. The difficulties of reconstructing past events are such that evidence adduced by the parties in order to resolve contentious issues will rarely provide the fact-finder with conclusive proof, and will to this extent be qualitatively deficient. Quantitative deficiencies may often be a consequence of the limited resources that parties will have at their disposal. In most cases, the scope of police investigations will be limited. It may not be practicable to pursue all lines of inquiry and obtain every piece of relevant evidence. These deficiencies mean that the verdict delivered by a tribunal will necessarily be the product of some degree of speculation and consequently there will be a risk of error. I will

\footnotetext{
${ }^{1}$ Including Queensland where the Queensland Law Reform Commission adopted a cautious view in relation to the adoption of the Uniform Evidence Acts' provisions concerning the use of identification parades; see Queensland Law Reform Commission, A Review of the Uniform Evidence Acts, Report No.60, (2005; QLRC).

${ }^{2}$ Evidence Bill 2008 (Vic).

${ }^{3}$ Evidence Act 2006.

${ }^{4}$ A. Stein, Foundations of Evidence Law, (2005, Oxford; OUP).
} 
suggest that the state has a moral duty to take reasonable steps to avoid convicting the innocent, and that this entails an obligation to ensure the use of procedures which mitigate qualitative and quantitative deficiencies in the evidence presented at trial. It is this moral obligation that provides the evaluative framework for the doctrinal developments considered in the second and third sections of this paper, which address respectively, issues of qualitative and quantitative deficiency.

\section{Procedural Norms and Eyewitness Identification Evidence}

Eyewitness identification evidence is both a commonplace and problematic feature of criminal trials. Although eyewitnesses are an important source of evidence, ${ }^{5}$ it is widely acknowledged that their attempts to identify others, even those with whom they are relatively familiar, are particularly prone to error. ${ }^{6}$ Despite the problems associated with this form of evidence and the frequency with which it is relied upon, the relevant academic literature often has a rather narrow focus. ${ }^{7}$ A significant shortcoming in much of the writing on the subject is the adoption of a parochial and procedurally atomistic approach. ${ }^{8}$ Existing law is

\footnotetext{
${ }^{5}$ An analysis of arrests at 10 police stations across England and Wales in a study conducted by C. Phillips. and D. Brown, Entry into the Criminal Justice System: a survey of police arrests and their outcomes, Home Office Research Study 185, (1998, London; Home Office), disclosed that: eyewitness evidence was provided by a police officer in $40 \%$ of all offences resulting in an arrest; in $23 \%$ of all cases eyewitness identification evidence was provided by an independent witness, the victim providing it in $18 \%$ of all cases and security personnel in $10 \%$ of cases; in sexual offences and offences involving the use of violence against the person the eyewitness testimony of the victim was the main source of evidence. A survey of those involved in Crown Court trials conducted by M. Zander and P. Henderson, The Royal Commission on Criminal Justice, Crown Court Study, Research Study No.19, (1993, London; HMSO), suggested that in 25\% of contested cases, eyewitness identification evidence formed and important element of the prosecution case.

${ }^{6}$ See E. Connors et al., "Convicted by Juries, Exonerated by Science: Case Studies in the Use of DNA Evidence to Establish Innocence After Trial" (1996, Washington D.C.; National Institute of Justice); Report to the Secretary of State for the Home Department of the Departmental Committee on Evidence of Identification in Criminal Cases, (1976, London; HMSO) (the Devlin Committee/Report); Law Commission of New Zealand, Evidence: Total Recall? The reliability of Witness Testimony, Miscellaneous Paper 13 (1999, Wellington; NZLC); Australian Law Reform Commission, Report No.26, Evidence (Interim), vol.2 (1985: ALRC, Canberra), chapter 11; Australian Law Reform Commission, Report No.38, Evidence (Final), (1987: ALRC, Canberra), chapter 15; Scottish Home and Health Department, Identification Procedure under Scottish Criminal Law, (1978, London; HMSO); N. Brooks, Law Reform Commission of Canada Study Paper, Pretrial Eyewitness Identification Procedures, (1983, Ottawa; LRCC).

${ }^{7}$ W. Twining, "Identification and Misidentification in Legal Processes: Redefining the Problem", in S. Lloyd-Bostock and B. Clifford (eds.) Evaluating Witness Testimony: Recent Psychological Research and New Perspectives, (1983, Chichester; Wiley), at 255-256.

${ }^{8}$ A. Roberts, "The Problem of Mistaken Identification: Some Observations on Process", (2004) 8 International Journal of Evidence and Proof 100; A. Roberts, "Towards a Broader Perspective on the Problem of Mistaken Identification: Police Decision-making and Identification Procedures", in
} 
taken as the starting point for much of the analysis, and the substantial body of empirical research on eyewitness identification provides the evaluative criteria. However, the agenda for empirical research appears to be largely defined by current legal practice, and consequently evaluation of law and procedure, and proposals for reform tend to be the product of a self-perpetuating cycle of limited scope. ${ }^{9}$ While empirical research will form part of a satisfactory and cohesive normative account of the procedural law concerning eyewitness identification evidence, the primary point of reference of such an account ought to be relevant legal standards. ${ }^{10}$

\section{(i) Adjudicative Accuracy and Epistemic Uncertainty}

Let us take as our starting point the uncontroversial proposition that subjects have a fundamental right to be acquitted of crimes which they did not commit. This might prompt us to say that securing accurate outcomes ought to be the principal objective of the criminal process; it ought to facilitate the conviction and punishment of the factually guilty, while ensuring that the factually innocent are acquitted. However, while we might accept that the innocent have such a right and adjudicative accuracy in all criminal proceedings is something to which we aspire, in practice, this is unattainable. Inquiries into past events are beset by epistemic uncertainty. As I have already pointed out, the evidence placed before fact-finders will be both qualitatively and quantitatively deficient. It will not provide conclusive proof of facts in issue and this qualitative deficiency will require the fact-finder to engage in a probabilistic reasoning process. There may be any number of explanations for quantitative deficiencies. I suggested in the introduction that the parties will generally have limited resources and that it will often not be possible to pursue all lines of inquiry which might yield relevant and probative evidence. Evidence may be lost or destroyed; tracing witnesses might prove to be difficult; those witnesses who are contacted might refuse to testify, and so on. While there may be nothing that can be done to address some of the causes of evidential deficiency, it will be possible through the use of appropriate procedures to enhance both the quantity and quality of some of the material on which a verdict must be delivered.

M. Freeman and B. Brooks-Gordon (eds.), Current Legal Issues, vol. 9, Law and Psychology, (2006, Oxford; OUP).

${ }^{9}$ There have been suggestions that the empirical eyewitness research agenda ought to be led by 'fundamental questions about the nature of the processes underlying eyewitness behaviour' rather than by aspects of legal practice and procedure; see N. Brewer, N. Weber and C. Semmler, "A Role for Theory in Eyewitness Research", in R. Lindsay, D. Ross, D. Read and M. Toglia (eds), The Handbook of Eyewitness Psychology, vol. 2, Memory for People, (2007, New Jersey; Lawrence Erlbaum).

${ }^{10}$ Twining, op. cit. n. 7. 
The overarching objective of adjudicative accuracy requires the adoption of identification procedures which mitigate, as far as possible, qualitative and qualitative deficiencies in evidence presented to fact-finders. ${ }^{11}$ This implies, firstly, the use of procedures which are known to produce the most reliable identification evidence. But it also requires those procedures to be used wherever doing so might produce evidence which is likely to lead to more accurate adjudication.

Qualitative and quantitative evidential deficiencies are likely to be exacerbated by the adversarial nature of proceedings. In adversarial systems, the trial constitutes the climactic centerpiece of the criminal process; a contest between the state and the defendant. ${ }^{12}$ The desire to prevail in this contest might induce a tendency in each of the parties to collect and present only evidence which advances its own interests, and also to suppress any evidence which serves the opposition's interests. Such problems are particularly acute in criminal proceedings in which one party, the prosecution, enjoys considerable systemic advantages, both in terms of the resources made available to it by the state, and the de facto control it has over access to most sources of evidence, or the means of generating it.

In the context with which we are concerned, this adversarial bias may lead the police to use identification procedures which increase the likelihood of obtaining evidence which supports the prosecution case by producing a positive identification of the suspect, but which are not designed to produce reliable evidence. ${ }^{13}$ Why might this tendency arise? To the detached observer, the use of a procedure which is likely to produce evidence of limited probative value, rather than an alternative procedure through which much more reliable evidence could have been procured, may seem irrational. One explanation for such decisions might be that the outcome of procedures which are conducted under conditions which control various forms of bias and suggestiveness are less predictable than those which do not take place under such conditions. In the early stages of an investigation, the need to obtain some form of identification evidence in order to construct a prima facie case against a suspect might be prioritised over concerns relating to the probative value of the evidence which might be obtained. This form of adversarial bias is evident in the procedures adopted by the police in the

\footnotetext{
${ }^{11}$ I do not suggest that this ought to be considered the only function of identification procedures, although it is perhaps the least controversial. Some have claimed, for example, that securing opportunities for participation in procedures ought to be considered an end in itself, to be pursued notwithstanding that participation could have no effect on the outcome of proceedings; see generally D. Galligan, Due Process and Fair Procedures: A Study of Administrative Procedures (1996, Oxford; Clarendon), 75-82.

${ }^{12}$ M. Damaska, Evidence Law Adrift, (1997, New Haven; Yale), 58-60.

${ }^{13}$ A suggestion made by the High Court of Australia in Alexander v R (1981) 34 ALR 289.
} 
English case, $R v$ Marcus. ${ }^{14}$ The suspect, M, was of unusual appearance and the police had difficulty in obtaining images for use in a video identification procedure of volunteers who bore a sufficient resemblance. The images had, with the agreement of the defence, been masked so as to obscure any significant differences in appearance. However, after consulting the Crown Prosecution Service, the police compiled a second set of unmasked images, which would be shown to the witness if $\mathrm{M}$ was not identified from the masked images. After failing to identify $M$ when shown the masked images, the witness perhaps unsurprisingly, picked him out when shown the unmasked images. At trial, a police witness conceded that M "blatantly" stood out and that the procedure was unfair. It came to light that the decision to show the witness unmasked images was a consequence of police frustration at the 'poor results' (presumably a low rate of suspect identification) which had been obtained when masked images had been used.

In addition to their effect of the quality of evidence that might be presented to the tribunal of fact, partisan interests might exacerbate quantitative deficiencies in the evidence. The difficulties of predicting the outcome of formal identification procedures with any certainty might lead the police to avoid conducting a procedure where there are other forms of evidence which might be used to prove identity; facial mapping evidence, possession of recently stolen property, DNA evidence etc. Although the idea will not be discussed in any detail here, these adversarial tendencies, and the relatively weak position of the suspect, provide the justification for giving suspects certain procedural rights; a right to procedures which might produce evidence which supports the defence case (a participatory right), and a right to procedures which produce the most accurate identification evidence (a protective right). ${ }^{15}$

\section{(ii) The Problem of Finite Resources}

The issue of resources is often overlooked by those advocating procedural reform and too readily invoked by policy-makers as a reason for rejecting proposals for reform. The finite resources made available to the criminal justice system generally, and the police in particular, may limit the state's capacity to adopt procedures which are likely to mitigate qualitative and quantitative evidential deficiencies.

The reality of finite resources presents a problem when we come to consider whether the state is under an obligation to use the most accurate possible procedures for obtaining identification evidence. If the innocent possess a

${ }^{14}$ [2004] EWCA Crim 3387; The Times, December 3, 2004.

${ }^{15}$ See A. Roberts, "Pre-Trial Defence Rights and the Fair Use of Eyewitness Identification Procedures", (2008) 71 Modern Law Review 331. 
fundamental right not to be convicted, and one of the principal functions of criminal procedure is to ensure adjudicative accuracy, it seems to follow that those who are accused of wrongdoing by the state have a right to the most accurate procedures for determining innocence and guilt. Where identification is, or might become, a central issue in a case, must the police always use procedures which are thought to produce the most reliable identification evidence? In other words, does a suspect have a right to the most accurate identification procedures?

One way of addressing the problem of finite resources is to claim that the suspect's right to the use of the most accurate identification procedures is a qualified right. Dworkin, for example, argues that an absolute right to the most accurate procedures for determining innocence and guilt would require the criminal justice system to have first call on the resources available to a government. ${ }^{16}$ Diversion of resources into the criminal justice system to give effect to this right would lead to a state of affairs in which there were insufficient resources to fund other aspects of governments' welfare obligations. Dworkin's solution to this problem is to suggest that the degree of procedural accuracy to which a suspect is entitled ought to be determined according to the extent of the harm to which procedural error would give rise. So those who are accused of the most serious crimes and who would suffer the greatest harm in the event of wrongful conviction would have a right to the most accurate procedures. As the gravity of the consequences of wrongful conviction subsides, so does the degree of procedural accuracy to which the suspect is entitled. However, Galligan has pointed out the flaws in this approach. ${ }^{17}$ If one acknowledges, as Dworkin does, that the innocent have a profound right not to be convicted, it seems rather strange to argue that there is no implicit right to the most accurate procedures for establishing innocence. As Galligan points out, procedures constitute the means of achieving some desired end and cannot, therefore, be extricated from the outcomes they produce. ${ }^{18}$ Dworkin's account of the extent of a suspect's right to procedural accuracy rests on an untenable distinction; it purports to acknowledge the suspect's right to an outcome while denying him a right to the best means of achieving it.

Galligan offers a more coherent account of the right to procedural accuracy, which addresses the problem of finite resources. A suspect's fundamental right not to be convicted of crimes of which he is innocent, necessarily implies a right to the most accurate procedures for determining that outcome. However, the problem of finite resources might be such that the state cannot always discharge its duty to provide suspects with such procedures. Galligan suggests that while finite resources cannot justify any dilution of a

\footnotetext{
${ }^{16}$ R. Dworkin, A Matter of Principle (1985, Oxford; OUP), ch.3.

${ }^{17}$ Galligan op. cit $\mathrm{n} .11,112-122$.

${ }^{18} \mathrm{Ibid}, 118$.
} 
suspect's rights in this respect, the state might be excused where it has done its best to give effect to the suspect's rights by using the most reliable procedures possible. ${ }^{19} \mathrm{He}$ argues further, that the state ought to be guided by fundamental principles of procedural justice - proportionality and equality - in allocating its resources. ${ }^{20}$ These principles require the state to use the most accurate procedures in respect of those facing the most serious allegations, and provide the same procedural guarantees to those who are similarly positioned. In practice, the accounts provided by Galligan and Dworkin appear lead to the same conclusion, though that provided by the former takes a more satisfactory route.

\section{(iii) The Forensic Inadequacies of the Criminal Trial}

The discussion so far has gravitated towards pre-trial identification procedures. However there are good reasons why, if our concern is the accuracy of identification evidence, we ought to focus on this stage of proceedings. The problems of reconstructing past events at trial were noted earlier and it was suggested that one of the underlying functions of procedure concerning eyewitness identification is to ensure that the tribunal of fact is presented with eyewitness identification evidence which is as reliable as possible. In many jurisdictions, it appears that the trial is still thought to provide satisfactory processes for evaluating the reliability of such evidence. However, as the Devlin Committee $^{21}$ noted, the traditional means of testing the veracity of evidence at trial - demeanour and cross-examination - are largely impotent when it comes to assessing this form of evidence. Identification evidence presented by an eyewitness is the product of a number of distinct cognitive processes: (i) perception of information during observation of the earlier relevant event, (ii) encoding of that information in the memory, (iii) a period of retention until, (iv) information is retrieved from the memory for an identification task, a process which involves ( $\mathrm{v}$ ) a comparison of the suspect and retrieved memory of the culprit. $^{22}$

The integrity of these processes can be undermined by various internal and external influences, and where this occurs a witness's capacity to make an

\footnotetext{
${ }^{19} \mathrm{Ibid}, 116$.

${ }^{20}$ Ibid, 119-127.

${ }^{21}$ op. cit. n.6.

${ }^{22}$ See the decision of the High Court of Australia in Craig $v R$ (1933) 49 CLR 429, at 446: "An honest witness who says 'the prisoner is the man who drove the car' whilst appearing to affirm a simple, clear and impressive proposition, is really asserting: (i) that he observed the driver; (ii) that the observation became impressed upon his mind; (iii) that he still retained the original impression; (iv) that such impression has not been affected, altered, or replaced... and; (v) that the resemblance between the original impression, and the prisoner is sufficient to base a judgment not of resemblance, but of identity."
} 
accurate identification may be compromised. It is not possible here to provide a detailed taxonomy of the factors that might have such an effect. In any case, only brief reference to the findings of empirical research is sufficient to indicate their nature and diversity. The age of the witness, ${ }^{23}$ a culprit and witness who are of different ethnic appearance, ${ }^{24}$ the presence of weapon ${ }^{25}$ and intoxication, ${ }^{26}$ for example, are all matters which appear to affect perception and encoding of information in a way that reduces the likelihood of a subsequent identification being accurate. Retained memories will decay over time and the malleability of memory is such that information provided by third parties after the original event can create 'new memories' which may later be recalled as facts observed during that event. Research has shown that the language used by an investigator when questioning a witness can influence the witness's recollections of events. ${ }^{27}$ During retention and retrieval, original memories can be lost or altered, new memories created and the witness's confidence in the accuracy of his recollections reinforced and inflated. ${ }^{28}$

As the Devlin Committee pointed out, eyewitness identification evidence presents a significant epistemic problem. The witness may claim that the suspect or defendant is the person he saw engaged in alleged wrongdoing, but how do we

${ }^{23}$ See, e.g. J. Searcy, J. Bartlett and A. Memon, "Influence of Post-Event Narratives, Line-up Conditions and Individual Differences on False Identification by Young and Older Eyewitness" (2000) 5 Legal and Criminological Psychology 219.

${ }^{24}$ For a review of the research on this effect see C. Meissner and J. Brigham, "Thirty Years of Investigating the Own-Race Bias in Memory for Faces", (2001) 7 Psychology, Public Policy and Law 3. For discussion of the implications for the US Constitution's Due Process clause of the cross-race effect see R. Natarajan, "Racialized Memory and Reliability: Due Process Applied to Cross-Racial Eyewitness Identifications" (2003) 78 New York University Law Review 1789.

${ }^{25}$ For a recent review of the relevant research see K. Pickel, "Remembering and Identifying Menacing Perpetrators: Exposure to Violence and the Weapon Focus Effect", in Lindsay et al, op. cit. n.9.

${ }^{26}$ D. Reid, J. Yuille and P. Tollestrup, "Recollections of a robbery: Effects of Arousal and Alcohol Unpon Recall and Person Identification", (1992) 16 Law and Human Behavior 425; J. Yuille and P. Tollestrup, "Some Effects of Alcohol on Eyewitness Memory", (1990) 75 Journal of Applied Psychology 268.

${ }^{27}$ E. Loftus and J. Palmer, "Reconstruction of Automobile Destruction: An example of the Interaction Between Language and Memory", (1974) 13 Journal of Verbal Learning and Verbal Behavior 585; E. Loftus and G. Zanni, "Eyewitness Testimony: The Influence of the Wording of a Question" (1975) 5 Bulletin of Psychonomic Science 86; R. Christiansen, J. Sweeney and K. Ochalek, "Influencing Eyewitness Descriptions" (1983), 7 Law and Human Behavior 59

${ }^{28}$ There is a vast literature on these issues. See e.g. E. Loftus, "Make-Believe Memories", American Psychologist, November 2003, 867. E. Loftus and G. Hoffman, "Misinformation and Memory: The creation of New Memories, (1989) 118 Journal of Experimental Psychology: General 100; A.Scoboria et al, "Immediate and persisting Effects of Misleading Questions and Hypnosis on Memory Reports, (2002) 8 Journal of Experimental Psychology: Applied 26; R. Belli, "Influences of Misleading Postevent Information: Misinformation Interference and Acceptance, (1989) 118 Journal of Experimental Psychology: General 72. 
establish how much information the witness perceived during the original event; how much of that information was stored in the memory; the extent to which it has been distorted or supplemented, or has decayed; exactly how closely does the witness's recollection of the culprit's appearance correspond with the appearance of the suspect or defendant? At trial, cross-examination might reveal the existence of some of the factors that are known to adversely affect identification accuracy, and experts can be called to explain the findings of research into such matters. Judicial warnings may be issued admonishing fact-finders of the need for caution in convicting on the basis of eyewitness identification evidence or directing their attention to the circumstances which suggest that the witness might be mistaken. ${ }^{29}$

However, none of these measures can tell us much about the state of the witness's memory. ${ }^{30}$ Much more can be achieved in this respect through the use of formal pre-trial identification procedures. The outcome of well-designed procedures, which require the witness to make choices about a number of individuals of similar appearance, all of whom, apart from the suspect are known to be innocent, may provide some indication of the quality of the witness's memory. Where the witness identifies the suspect during such a procedure, there is a satisfactory basis (that is, evidence derived from the suspect's memory rather than evidence concerning the presence or absence of factors associated with reliability generally) for inferring both that the witness's memory is accurate, and consequently, that the suspect is the person that the witness saw engaged in wrongdoing. That inference may be more reliable where procedures are conducted at the earliest opportunity. The shorter the period between a witness's perception of the offender and any procedure designed to elicit reliable identification evidence, the less likely it is that a witness will have been exposed to situations which give rise to a risk of memory distortion.

To summarise, maximization of the quantity and quality of evidence presented at trial ought to constitute fundamental objectives of procedural law

\footnotetext{
${ }^{29}$ In Neil v Biggars 409 US 188 (1972), for example, the Supreme Court suggested that the following factors might be relevant an assessment of the reliability of any identification evidence: (i) the witness's view of events and attentiveness, (ii) the accuracy of the description provided by the witness, (iii) the degree of certainty with which the identification was made, (iv) the length of time that had elapsed between the crime and the identification procedure. This decision has been criticized on the grounds that they are out of step with the findings of subsequent empirical; see e.g. G. Wells and D. Quinlivan, "Sugegstive Eyewitness Identification Procedures and the Supreme Court's Reliability Test in Light of Eyewitness Science: 30 Years Later", Law and Human Behavior (in press).

${ }^{30}$ Devlin Report, op. cit. n.6, paragraph 4.25; see also J. Jackson, "The Insufficiency of Identification Evidence Based on Personal Impression", [1986] Criminal Law Review 203; T. Dillickrath, "Expert Testimony on Eyewitness Identification: Admissibility and Alternatives", (2001) 55 University of Miami Law Review 1059, at 1065; R. Wise, K. Daupinais and M. Safer, "A Tripartite Solution to Eyewitness Error", (2007) 97 Journal of Criminal Law and Criminology 807, 828-30.
} 
relating to eyewitness identification. The forensic inadequacies of the criminal trial are such that efforts to ensure the quality of eyewitness identification evidence ought to focus primarily on the pre-trial procedures. If we acknowledge that the innocent have a fundamental right not to be convicted we must accept that suspects have a right to the use of procedures that are likely to produce the most reliable identification evidence. However, the state may be excused for failing to give effect to that right when faced with significant practical obstacles, including the problem of finite resources. While the problem of reliability has long been an issue that has been associated with eyewitness identification evidence, the state's (and more pointedly, police) control over the means of generating such evidence is an issue that has not received the same degree of attention. But effective pursuit of the ends of adjudicative accuracy requires some thought to be given to ensuring that formal identification procedures are conducted where the outcome might have a bearing on the accuracy of the fact-finding process.

We now have a framework within which we can consider the extent to which procedural developments in various jurisdictions further the objectives of maximizing the quality and quantity of identification evidence which is made available to the fact-finder. We start with the former and consider the adoption in some US jurisdictions of the sequential lineup, and legislative provisions in Australia and New Zealand which establish evidential exclusionary presumptions where formal pre-trial procedures are not conducted. The final section considers the extent to which the idea of a right to participate in procedures is reflected in legal procedures. It examines the problems that have been encountered in attempting to regulate the decision-making process which determines whether or not formal identification procedures are conducted in England and Wales.

\section{Mitigating Qualitative Deficiency}

\section{(i) Sequential Procedures and Blind Administrators}

For some time, those engaged in empirical research have been arguing for the adoption of 'sequential line-ups' rather than more traditional procedures in which the subjects are presented simultaneously. In addition to the individual presentation of subjects, the sequential lineup differs fundamentally from traditional procedures by requiring the witness to make a decision in relation to one subject before being shown the next. As soon as the witness makes an identification the procedure is concluded and the witness is not permitted to see the remaining subjects. Those advocating the use of this procedure point to research that suggests its use will lead to fewer instances of 'false positive' identification. In other words, it appears that innocent suspects are less likely to be mistakenly identified in a sequential procedure than in a traditional 
simultaneous procedure. ${ }^{31}$ Although this finding has been replicated across a number of studies, findings concerning the effect that the use of sequential procedures has on the rate of accurate identifications (that is, the identification of the culprit) is rather more inconsistent. The majority of the research suggests that the use of this form of procedure has a negligible effect on the rate of accurate identification, but there are some studies in which its use has been found to significantly reduce the rate of such outcomes. ${ }^{32}$ In jurisdictions in which the rhetoric of crime control is valuable political currency, one might expect some resistance to the adoption of procedures which are likely to result in the conviction of fewer factually guilty suspects, notwithstanding the likelihood that use of such procedures might also produce a significant reduction in the incidence of wrongful conviction. However, the sequential procedure has been adopted in a number of jurisdictions in the United States. ${ }^{33}$

Publication by the National Institute of Justice of guidelines for conducting pre-trial identification procedures (hereafter 'the NIJ Guide') has been instrumental in the move towards the use of the sequential lineup. ${ }^{34}$ The NIJ Guide provides model procedures which were drafted by a working group comprising psychologists, prosecutors and police officers. Although the document contains instructions for conducting both simultaneous and sequential line-ups, it expresses a preference for neither. However, some have argued that the US constitutional Due Process clause requires exclusive use of the sequential line-up procedure on the grounds that it reduces the incidence of false positive identification. ${ }^{35} \mathrm{We}$ noted earlier though, that any guarantee of procedural accuracy must be subject to some qualification; the state may be excused for a

\footnotetext{
${ }^{31}$ See N. Steblay et al., "Eyewitness Accuracy Rates in Sequential and Simultaneous Lineup Presentations: A Meta Analytic Comparison", (2001) 25 Law and Human Behavior 459. For a review of the relevant research findings and the limitations of the procedure, see P. Dupuis and R. Lindsay, Radical Alternatives to Traditional Lineups, in Lindsay et al, op. cit. n.9, 184-192.

${ }^{32}$ See e.g. T. Valentine, S. Darling and A. Memon, "Do strict rules and moving images increase the reliability of sequential identification procedures?, (2007) 21 Applied Cognitive Psychology 933.

${ }^{33}$ e.g Wisconsin: 2005 Wisconsin Act 60; New Jersey, see Attorney General's Guidelines, http://www.state.nj.us/lps/dcj/agguide/photoid.pdf (accessed September 2008). For a sceptical report on the effectiveness of the procedure, see S. Mecklenburg, Report to the Legislature of the State of Illinois: The Illinois Pilot Program on Sequential Double Blind Identification Procedures (2006); http://www.chicagopolice.org/IL\%Pilot\%20Eyewitness\%20ID.pdf (accessed September 2008). However, see D. Schacter et al., "Policy Forum: Studying Eyewitness Investigations in the Field", (2007) 32 Law and Human Behavior 3; K. Findley, "Innocents at Risk: Adversary Imbalance, Forensic Science, and the Search for Truth", (2008) 38 Seton Hall Law Review 893, 958-964 for a critical analysis of the methodology employed in this research.

34 "Eyewitness Evidence: A Guide for Law Enforcement", (1999, Washington DC; National Institute of Justice).

${ }^{35}$ See M. R. Headley, "Long on Substance, Short on Process: An Appeal for Process Long Overdue in Eyewitness Lineup Procedures", (2002) 53 Hastings Law Journal 681.
} 
failure to conduct the most accurate identification procedures where it faces significant practical obstacles to doing so. This appears to be addressed in the Guide. While it states that the underlying purpose of pre-trial identification procedures is to obtain 'accurate identification and non-identification decisions', 36 the document's preamble suggests that those which it addresses should give 'careful consideration' both to the procedures set out in the NIJ Guide and to unique local conditions and logistical circumstances. ${ }^{37}$ Nevertheless, the Guide might be criticised for its prevarication. If the drafters accepted the validity of the science on which the sequential lineup is based, a preference ought to have been expressed for that procedure, subject to some qualification relating to the practicability of conducting the procedure.

If mitigation of qualitative deficiency is a fundamental objective of eyewitness identification procedures, preference for either sequential or simultaneous procedures ought to be determined primarily by the net gain in accuracy that might be achieved. If the use of sequential procedures results in fewer false positive outcomes, while producing a relatively smaller decrease in the rate of accurate positive identification, as the findings of various studies suggest, their adoption would lead to an overall increase in outcome accuracy compared with the use of simultaneous procedures. ${ }^{38}$ One explanation of the significant reduction in the rate of false positive identification produced by sequential lineups when compared with simultaneous presentation concerns the judgment strategy that the witness may use in the respective procedures. Simultaneous presentation of subjects allows the witness to compare the persons appearing in the procedure to one another. It is suggested that this might lead to the witness selecting the subject who bears the closest resemblance to the culprit, though that resemblance may not, in fact, be particularly close. The suspect may be identified on the basis that he is the 'best candidate'.

Because in the sequential lineup the witness is shown only one image at a time and is required to make a decision in relation to each image before the next is shown, the opportunity to compare subjects does not arise. Because intra-subject comparison is not possible, any identification is more likely to based on there being a close similarity in the suspect's appearance and the witness's recollection of the culprit. It has been suggested that, as identification of a suspect through a shallow relative judgment may amount to no more than speculation on the part of

\footnotetext{
${ }^{36}$ Op. cit. n.34, 29

${ }^{37} \mathrm{Ibid}$, iii.

${ }^{38}$ This type of calculus might be rather more difficult if, for example, the use of sequential procedures brought about a roughly equal decrease in false positive identifications and accurate positive identifications respectively. In such circumstances the adoption of the procedure might still be justified but on the grounds of the appropriate allocation of risk between suspect and state. It might be considered preferable to sacrifice a reduction in the rate of accurate positive identifications for a corresponding reduction in the rate of false positive identification.
} 
the witness, a higher rate of false identification might be expected. This kind of speculation on the part of the witness might be expected to lead to identification of suspects from time-to-time. If the opportunity to speculate is removed then the rate of accurate identification may fall. However, suppose further research were to reveal that the use of sequential lineups brought about a roughly equal reduction in the rate of false and accurate positive identifications; that its use would produce no net gain in procedural accuracy. Some might still advocate adoption of the sequential lineup on the grounds that its use would lead to an appropriate allocation of the risk of error between suspect and state. A reduction in the rate of accurate positive identifications might be viewed as a acceptable price for greater protection against the risk of false positive identification.

In England and Wales regulation of pre-trial identification procedures is provided by Code D of the Codes of Practice issued under section 66 of the Police and Criminal Evidence Act 1984. The Code prescribes in some detail various procedures that may be used by the police to obtain identification evidence from an eyewitness, and it establishes a clear hierarchy among those procedures. Following revision of the Code in 2002, video identification procedures, in which images of the suspect and innocent fillers are presented sequentially, supplanted the traditional identification parade as the principal identification procedure. ${ }^{39}$ The video identification procedure, differs significantly from the sequential lineup described in the NIJ Guide. Although the video identification procedure involves the sequential presentation of single images the witness is not required to make a decision in respect of one image before being permitted to view the next. Indeed, the provisions of the Code require the witness to view the entire set of images at least twice before making any identification, and also that officers conducting the procedures inform witnesses that there is no limit on the number of times that they may see the sequence, or part of the sequence, of images. ${ }^{40}$ Only minor modification of the instructions given to witnesses would be needed for the video identification procedure prescribed to incorporate the essential features of a sequential lineup and this would appear to have no significant resource implications. If, as the research suggests, a sequential lineup is the most accurate identification procedure, some may argue that continued failure to make the changes amounts to a violation of a suspect's right to the use of the most accurate identification procedures.

Similar claims regarding a suspect's procedural rights might also follow the failure to adopt procedures which are designed to ensure that those administering procedures, whether sequential or simultaneous, are unaware of the

\footnotetext{
${ }^{39}$ See paragraph D3.14 of the current version of the Code (issued 2008) which provides that the "suspect shall initially be offered a video identification unless it is not practicable or an identification parade is more practicable and more suitable..."

${ }^{40}$ Code D, Annex A, paragraph 11.
} 
identity of the suspect. Research suggests that administrators who possess this knowledge may inadvertently provide cues which may indicate to the witness which of the participants in the procedure is the suspect. ${ }^{41}$ If the use of a 'blind' administrator does, in fact, eliminate any bias towards selection of the suspect caused by cues provided unconsciously by administrators, the only grounds for opposing adoption of this measure can be that it imposes an unreasonable cost. ${ }^{42}$ Although blind procedures are not included in the recommendations set out in the NIJ Guide, on the grounds that they may prove to be impractical in some jurisdictions, there is an acknowledgement that the future use of this form of procedure is something that might be kept under review. ${ }^{43}$

\section{(ii) Securing Procedural Accuracy through Exclusionary Rules}

It was suggested in the introductory section that much of the literature on the legal response to the problem associated with eyewitness identification evidence tends to adopt an atomistic approach. This kind of approach fails to acknowledge that such evidence will be the subject of a series of decision-making processes, and that each decision-maker may be influenced by the nature of the decision-making processes which precede or follow his or her decision. ${ }^{44}$ The value of formal identification procedures in furthering the objective of ensuring that the evidence presented at trial is as reliable as possible is contingent on the quality of the decision-making process which determines when they are used. It was suggested earlier that the adversarial nature of proceedings and the desire to construct a prima facie case against a suspect might lead the police to adopt procedures which do not produce identification evidence which is particularly probative. Where decision-makers are aware that the use of such procedures will have adverse effects there may be an incentive to use more reliable procedures. The corollary, of course, is that where no significant adverse consequences are likely to follow the use of less reliable procedures there is little incentive to use the more reliable procedures, those which provide the suspect with greater protection

\footnotetext{
${ }^{41}$ M. Phillips, B. McAuliff, M. Kovera and B. Cutler, "Double-blind Photoarray Administration as a Safeguard against Investigator Bias" (1999) 84 Journal of Applied Psychology 940. See also, L. Garrioch and C. Brimacombe, "Line-up Administrators Expectations: Their Impact on Eyewitness Confidence" (2001) 25 Law and Human Behavior 299.

${ }^{42}$ See M. Risinger, "Innocents Convicted: An Empirically Justified Factual Wrongful Conviction Rate", (2007) 97 Journal of Criminal Law and Criminology 761, who suggests that this is reform would be 'cost-free' in terms of acquittal of the factually guilty and ought to be adopted. Other have suggested that although there may be 'logistical problems' there are various ways in which these might be circumvented, see e.g. R. Wilcock, R. Bull and R. Milne, Witness Identification in Criminal Cases: Psychology and Practice, (2008, Oxford; OUP), 131-3.

${ }^{43}$ NIJ Guide, op. cit. n.34, p.9.

${ }^{44}$ See further, A. Roberts, Current Legal Issues, op. cit. n.8.
} 
against the risk of mistaken identification. Observations on the exercise of judicial discretion made by the Australian Law Reform Commission are interesting in this respect: ${ }^{45}$

"A reading of reported Australian cases leaves the impression of a reluctance on the part of trial judges to exclude eyewitness identification evidence, however unreliable or weak it may seem. Instead reliance is placed on the warning to the jury and appellate courts give lengthy statements about the appropriate detail of such warnings. So, even evidence of identification which is so liable to being mistaken that it would be 'extremely dangerous for a jury to assign any probative value to it' may be properly admitted as long as a jury is given a warning in such terms." ${ }^{, 46}$ [internal references omitted]

Although concerned with the exercise of discretion by Australian judges, these observations have a salience which extends beyond the boundaries of that jurisdiction. In England and Wales, trial judges have discretion to exclude prosecution evidence where its reception would have an adverse effect the fairness of proceedings. ${ }^{47}$ While failure to follow the provisions of Code D might, in theory, lead to the exclusion of identification evidence on which the prosecution proposes to rely, the appellate courts rarely interfere with a trial judge's decision to admit identification evidence where the police have breached the Code.

$R v$ Williams $^{48}$ provides a particularly striking example of the appellate courts' laissez-faire approach in relation to review of the exercise of judicial discretion. W had been convicted of attempted robbery. The victim had been waiting at a bus stop when she was engaged in conversation by a man who gradually struck a more menacing tone. He eventually threatened to stab her with a hypodermic needle and demanded her cash and jewelry. She managed to escape and provided the police with a description of the offender over the telephone. Police officers making their way to the crime scene passed $\mathrm{W}$, who immediately took flight and was detained after a short pursuit. There were significant discrepancies in the description of the culprit provided by the victim and W's appearance. The culprit had been described as a clean-shaven man with a local London accent, who wore brown shoes. W had a very distinctive Scottish accent, two to three days stubble, and had been wearing black shoes. If these

\footnotetext{
${ }^{45}$ Australian Law Reform Commission, Evidence, Report No.26. Interim, (1985, Canberra; ALRC).

${ }^{46}$ Ibid, [424].

${ }^{47}$ Police and Criminal Evidence Act 1984, section 78.

${ }^{48}$ [2003] EWCA Crim 3200.
} 
discrepancies give rise to concerns over identification of $\mathrm{W}$ as the culprit, the manner in which the witness was invited to identify $\mathrm{W}$ undoubtedly compounds those concerns. The procedure followed by the police breached various provisions of Code D, in respect of which the Court of Appeal observed that:

"... the identification took place in circumstances which were clearly capable of resulting in the victim ... being, in effect, by the circumstances, told that this was the person who had attempted to rob her, that is by reason of the fact that it was clear that he had been apprehended, was in handcuffs and was surrounded by police officers. A clearer way of pointing out to her who it was that the police sought her to identify could not have been imagined."49

Although the prosecution case rested entirely on the identification evidence provided by the victim, the police had disregarded important provisions of Code D which were designed to ensue the quality of the evidence, and it was accepted that the police could not have adopted a procedure which was any more suggestive, the Court of Appeal was satisfied that the evidence had been properly admitted. It concluded that, as the witness had had an opportunity to observe the offender at close quarters for some time, and the jury had been adequately warned of the need for caution in convicting on the basis of the witness's identification evidence, it could not be said that the jury's verdict was unsafe.

It was suggested in the previous section of this paper, that the fundamental right of innocent suspects not to be convicted necessarily implies a right to the most accurate procedures for determining innocence and guilt. However, the state might be excused for failing to give effect to that right where it is confronted with significant practical obstacles. In other words there it has a duty to ensure that the police use the most reliable procedure from the range of procedures which are, in the circumstances, practicable. But this cannot be the extent of the right. The procedures used must meet some minimum threshold of accuracy. Some pre-trial procedures might be so unreliable that the resulting evidence is of little or no probative value and, practical obstacles notwithstanding, their use will be inconsistent with the procedural guarantees that are implied by a suspect's fundamental right not to be convicted of crimes of which he is innocent. In light of the inadequacies of the trial as a means of satisfactorily evaluating eyewitness identification evidence, we might conclude that the use of such procedures gives rise to an unacceptable prejudicial effect.

Williams appears objectionable on two grounds. The first is that the police failed to use the most reliable procedure that could have been used in the

${ }^{49}$ at [12]. 
circumstances. Whether or not the formalities had been complied with, the suspect was effectively under arrest, and in such circumstances a formal procedure could (and should) ${ }^{50}$ have been conducted under conditions which controlled the risk of error. The second objection is that the procedure used was so suggestive that it could reasonably be concluded that no probative value ought to have been attached to the resulting evidence. Indeed, we might go further and suggest that such was the importance of the evidence obtained through the use of that procedure, it comprising the prosecution case against the defendant, that allowing a jury to consider it in reaching its verdict deprived $\mathrm{W}$ of a fair trial.

One way of mitigating qualitative deficiencies in the evidence adduced at trial is to require the use of pre-trial procedures which are known to produce reliable identification evidence as a condition of admissibility. This is the approach taken in those Australian jurisdictions which have adopted the Uniform Evidence Act, ${ }^{51}$ and following enactment of the Evidence Act 2006, is the prevailing approach in New Zealand. ${ }^{52}$

\section{(a) Australia: Uniform Evidence Acts}

In Australia, the broad position is that admissibility of 'visual identification" ${ }^{, 53}$ is predicated on there having been an 'identification parade' held prior to trial. This position is, however, qualified. Evidence is admissible notwithstanding the failure to conduct an identification parade where it would not have been reasonable to conduct one, ${ }^{54}$ or where the defendant refused to participate in one. ${ }^{55}$ The statute provides a non-exhaustive list of factors which the court is required to take into account in determining the reasonableness of a failure to conduct an identification parade. ${ }^{56}$ These include: the nature and gravity of the offence concerned; the importance of the evidence; the defendant's failure to co-operate in the parade, and the practicality of conducting a parade in view of the relationship between the witness and defendant.

\footnotetext{
${ }^{50}$ Code D requires a video identification procedure to be conducted where there is sufficient information to justify the arrest of the individual for suspected involvement in the offence; paragraph D3.4.

${ }^{51}$ Evidence Act 1995 (Cth) section 114; Evidence Act (NSW) section 114; Evidence Act 2004 (NI) section 114.

52 Evidence Act 2006, section 45.

53 'Visual identification' is defined in section $114(1)$ as "identification evidence relating to an identification based wholly or partly on what a person saw but does not include picture identification evidence".

${ }^{54}$ Section 114(2)(b).

${ }^{55}$ Section 114(2)(c).

${ }^{56}$ Section 114(3).
} 
If we consider this legislation in light of the normative principles discussed earlier, in some respects it appears to provide a more satisfactory approach than that taken by English criminal procedure. Among its virtues is that it establishes a prima facie presumption of exclusion where eyewitness identification evidence is obtained by procedures that do not offer the degree of procedural accuracy which is provided by an identification parade. Further, the exceptions to this presumption closely reflect the normative position that the state may be excused for failing to provide the suspect with the most accurate procedures where it faces significant practical obstacles to doing so. For example, by referring to the nature and gravity of the offences being investigated as a factor which is relevant to an assessment of the reasonableness of a failure to conduct a parade, the issue of finite resources is acknowledged. Presumably, in taking account of this factor trial judges will, in effect, be applying some form of proportionality principle. The more serious the allegation against a defendant, the greater the need to ensure that the most accurate identification procedures are used, and the less excusable any failure to do so.

This approach might, however, be vulnerable to criticism that trial judges will be deciding the appropriate allocation of resources, and that this is a political issue which ought to be determined by a democratically elected and accountable institution. Furthermore, devolving decisions over the allocation of resources to trial judges will probably result in a degree of inconsistency and this may leave the state open to charges of failure to discharge its duty to treat all of those who fall under suspicion of wrongdoing with equal concern and respect. In contrast, English criminal procedure appears to promise all suspects a right to the most accurate identification procedures irrespective of the nature of the allegations that they face. ${ }^{57}$ This failure to address the issue of limited resources in the regulatory provisions has led to ad hoc adjudicative legislating. This has given rise not only to inconsistent judicial decision-making but also an undesirable lack of clarity in the relevant principles. In some cases the courts have suggested that the reality of finite resources means that the procedural guarantees provided by Code D must be qualified in cases involving less serious allegations ${ }^{58}$ while judgments in other cases suggest that full force of the provisions apply irrespective of the gravity of the offences concerned. ${ }^{59}$

\footnotetext{
${ }^{57}$ Paragraph D3.12 requires a video identification to be conducted "whenever a suspect disputes identification".

${ }^{58}$ e.g. Barnes v Chief Constable of Durham [1997] 2 Cr App R 505; Karia v DPP [2002] EWHC 2175 Admin.

${ }^{59}$ e.g. North Yorkshire Trading Standards v Williams (QBD November 3, 1994) 159 JP 383. See also, T. Watkin, "In the Dock - A Overview of the Decisions of the High Court on Dock Identifications in the Magistrates' Court" [2003] Criminal Law Review 463.
} 
A more fundamental problem with the Uniform Evidence Act is that it makes reception of visual identification evidence conditional on a procedure - 'an identification parade' - which it does not define or prescribe, having been conducted. Defining the procedure on which admissibility is predicated in only the most general terms undermines the purpose of the adoption of an exclusionary approach; that of ensuring that the evidence presented to the tribunal of fact is as reliable as possible. This is because it is possible for a procedure which has the appearance of an 'identification parade' and might be appropriately described as such to be conducted in a manner that produces evidence of little, if any, probative value. $^{60}$

\section{(b) New Zealand: Evidence Act 2006}

Although the statutory scheme governing the admissibility of eyewitness identification evidence in New Zealand includes an exclusionary provision, it differs significantly from that which is provided by the Australian uniform legislation. Section 45(2) of the Evidence Act 2006 establishes a presumption that visual identification evidence will be excluded where: (i) it was obtained through means other than a 'formal procedure', and (ii) there was no 'good reason' for not following such a procedure. The Act differs from the Australian legislation in a number of respects. First, it provides an exhaustive list of reasons which constitute 'good reasons' for not following a formal procedure. ${ }^{61}$ However, where identification evidence has been obtained by means other than a formal procedure, and there is no good reason for the failure to conduct such a procedure, the prosecution may still be able to rely on the evidence if it is able to prove beyond reasonable doubt that the evidence is reliable.

However, the operation of this 'safety valve' might prove to be problematic. Reliability is a relative rather than an absolute concept. Evidence may be more or less reliable; more or less helpful in assisting the fact-finder to evaluate the likelihood of the truth of the proposition in support of which it is adduced. Presumably, the prosecution will be required to show that the evidence which it seeks to adduce meets is sufficiently reliable. But how reliable must it be before it can be received? Where should the threshold of reliability for the

\footnotetext{
${ }^{60}$ It has been suggested that the characteristics of 'an identification parade' may be determined by recourse to other bodies of law, common law and statute; see J. Anderson, J. Hunter and N. Williams, The New Evidence Law (2002, Chatswood, NSW; Butterworths), 389-391. However, the nature of the common law judicial legislating process is unlikely to lead to procedures which are grounded in the relevant scientific findings. As to the problem of defining identification procedures in primary legislation, e.g. in section 3ZM(6) Crimes Act 1914 (Cth), see main text below.

${ }^{61}$ Section 45(4)
} 
purposes of determining admissibility be set? We have already noted the forensic inadequacies of the criminal trial when it comes to the evaluation of eyewitness identification evidence. The reasons why the trial provides an ineffective process for evaluating eyewitness evidence ought to prove a significant obstacle for prosecution attempts to prove the reliability of eyewitness identification evidence. In some cases there may be external factors which suggest that identification made by the witness was less susceptible to the risk of error, but as we noted previously, these factors reveal nothing about the integrity of the cognitive processes that produced the evidence. It provides us with no indication as to which class of individuals the witness belongs; those who will identify accurately in such circumstances or those who will make errors. In view of this the burden on the prosecution appears to be an onerous one.

It was suggested above that making the admissibility of an identification evidence conditional on an 'identification parade' having been conducted appears to be a fundamental flaw in the Uniform Evidence Act. In New Zealand, admissibility is predicated on a 'formal procedure' having been followed. Some of the characteristics of such a procedure are prescribed in section 45(3) and these may be supplemented by further prescription in secondary legislation. In this event, compliance with any such regulation also becomes a condition of admissibility. ${ }^{62}$

Defining or prescribing elements of formal procedures in primary legislation is not without its problems. Prescription contained in primary legislation is likely to become much more entrenched than that provided in delegated legislation and statutory codes. Ensuring that procedures set out in primary legislation reflect developments in empirical research is likely to be a more difficult task than it would be if those procedures were set out in subordinate legislation. Under section 45 of the Act, evidence obtained through a sequential lineup appears to be presumptively inadmissible. Section 45(3)(b) provides that a 'formal procedure' is one in which 'the person to be identified is compared to no fewer than 7 other persons who are similar in appearance to the person to be identified" [emphasis added]. What distinguishes a sequential lineup from the more traditional forms of identification procedure, such as a parade, is that it is designed to prevent the witness comparing those who appear in the procedure. An answer to this might be to point to the safety valve which permits identification evidence obtained other than by following formal procedure defined in the Act and any supplementary regulations to be received where the prosecution can prove its reliability beyond reasonable doubt. This may be a course of action which is open to trial judges, but reliance on the exercise of judicial discretion in this way would be an unsatisfactory proxy for substantive

${ }^{62}$ Section 45(3)(g). 
procedural reform, particularly where the product of those procedures is a form of evidence which is acknowledged to be problematic.

\section{Mitigating Quantitative Deficiencies}

We now turn to the second underlying function of the law relating to eyewitness identification evidence; mitigation of quantitative evidential deficiencies. It was suggested earlier that if procedures were to further the end of securing adjudicative accuracy, their underlying objectives ought to mitigate as far as possible, the qualitative and quantitative deficiencies in the evidence presented to the fact-finder. This implied not only the use of procedures known to produce the most accurate identification evidence, but also that eyewitness identification procedures should be used wherever they might produce evidence which would further the ends of adjudicative accuracy. However, we noted that in an adversarial contest the desire to prevail might lead the parties to suppress evidence. It was suggested that the difficulty of predicting the outcome of a properly conducted formal procedure may lead the police to avoid conducting one where there are alternative forms of evidence which might be adduced to prove identity. However, where there are witnesses available, the failure to conduct identification procedures deprives a defendant of the opportunity to obtain evidence which might support his case.

\section{(i) A Right to Participate in Procedures?}

One way of ensuring that a procedure is conducted in such circumstances is to provide the suspect with a right to participate in procedures where doing so might produce exculpatory evidence. However, this idea does not appear to have secured much of a foothold in any jurisdiction. In its development of Due Process clause jurisprudence, the US Supreme Court has confined itself to considering the reliability of the identification evidence on which the state has relied rather than the issue of participation. The prospect of recognition of this kind of participatory right as an element of a suspect's broad right to a fair trial under Article 6 of the European Convention on Human Rights appears more promising. The 'equality of arms' principle which pervades the European Court's Article 6 jurisprudence requires that the parties be given equal opportunities to present evidence. ${ }^{63}$ This implies that where the state has exclusive control over the means of producing that evidence, as it does in respect of the facilities required to conduct an identification procedure, it has a duty to accede to a suspect's request for an

\footnotetext{
${ }^{63}$ See generally J. Jackson, "The Effect of Human Rights on Criminal Evidentiary Processes: Towards Convergence, Divergence or Realignment?” (2005) 68 Modern Law Review 737.
} 
identification procedure. ${ }^{64}$ The idea that a suspect has a right to participate in an identification procedure is one that does not appear to have been argued before English appellate courts. However, the notion of such a right appears consistent with the English Court of Appeal's assertion in $R v$ Nicholson $^{65}$ that identification procedures are a facility administered by the police for the benefit of both parties:

'Despite what might at first be thought to be the purpose of an identification parade, namely that it is a method or procedure by which the police seek to obtain evidence for the purposes of prosecuting suspects, as opposed to a service performed impartially for prosecution and defence, this court in various of its previous decisions, leaned towards the latter view on the basis, it seems, that a parade may produce negative evidence favourable to an accused which the defence are incapable of generating for themselves. ${ }^{66}$

Despite these observations, there are various signs of an ingrained perception that the purpose of formal identification procedures is to ensure the reliability of identification evidence tendered by the prosecution. In $R v$ Thomas, ${ }^{67}$ for example, at the defendant's trial for armed robbery the prosecution relied on facial mapping evidence to prove identity. Although there were a number of eyewitnesses who had observed the culprit, the police failed to arrange any identification parades. In respect of this failure the Court of Appeal observed:

"There appears to us to be a distinction between a case where the Crown relies for identification on a witness who could have taken part in an identification parade, and cases, such as the present, where the Crown does not rely on an identification by any such witness and seeks to identify the defendant by other evidence. The advantage to a defendant in the former situation, of having a relevant witness fail to pick him out in an identification parade, is greater than any advantage in the latter situation of having a person, who might have been an identifying witness but on the whom the Crown is not relying for identification, fail to identify the defendant on a parade" ${ }^{68}$ (original emphasis)

What the court appears to be suggesting, is that the probative value of a witness's failure to pick out the suspect on an identification parade is affected by a prosecution decision not to rely on that witness in its case. The reasoning

\footnotetext{
${ }^{64}$ See further Roberts, op. cit. n. 15 .

${ }^{65}$ [1999] EWCA Crim 2101.

${ }^{66} \mathrm{Ibid},[28]$.

${ }^{67}$ Unreported, November 22, 1999.

${ }^{68}$ supra at [43].
} 
appears to be grounded in an idea which is traditionally associated with adversarial proceedings; ${ }^{69}$ that the parties have a quasi-proprietary interest in the witnesses and the evidence that they provide. In Thomas, the eyewitnesses appear to have been viewed as a source of evidence for the prosecution rather than neutral repositories of information which might benefit either party.

In some jurisdictions it has been made clear that identification procedures serve an important exculpatory function. The NIJ Guide, for example, states that the function of identification parades (or lineups) is to provide for 'accurate identification or non-identification. ${ }^{70}$ It recommends that witness be instructed before the procedure is conducted, that absolving the innocent from suspicion and convicting the guilty are equally important objectives. ${ }^{71}$ In addition, it suggests that witnesses be told that the person seen previously may or may not appear in the procedure and that the police investigation will continue regardless of whether or not an identification is made. ${ }^{72}$ In other jurisdictions, however, the language used in relevant regulatory provisions implies that identification procedures fulfill the more limited function of ensuring the reliability of prosecution evidence. In New Zealand, for example, the statutory definition of a formal identification procedure refers to the suspect as 'the person to be identified" ${ }^{73}$ and the witness as 'the person making the identification.' These labels appear, respectively, to be inconsistent with a conception of witnesses as a source of evidence which might assist either of the parties, and formal procedures as the means through which the parties may obtain that evidence.

In England, the introductory paragraph of Code D explains that the Code "concerns the principal methods used by the police to identify people in connection with the investigation of offences..." (emphasis added). ${ }^{74}$ However, in the early versions of the Code the suspect's right to participate in an identification procedure was explicit. The version of the Code issued in 1991 provided that "In a case which involves disputed identification evidence a parade must be held if

\footnotetext{
${ }^{69}$ On the proprietary concept of evidence and its sources see Damaska, op. cit. n. $12,76-77$.

${ }^{70}$ NIJ Guide, op. cit. n.34, 29.

${ }^{71}$ Ibid., 32.

72 Ibid.

${ }^{73}$ Evidence Act 2006, section 45(3). The statutory provisions rather confusingly use the term 'the person to be identified' both in provisions which clearly refer to the suspect and in those which appear to relate to the offender. Section 45(3)(c) provides that a formal procedure is one in which "no indication is given to the person making the identification as to whom among the persons in the procedure is the person to be identified". The term "person to be identified" in this provision is a reference to the suspect who appears in the procedure. However, section 45(3)(d) provides that such a procedure is one in which "the person making the identification is informed that the person to be identified may or may not be among the persons identified in the procedure". Here "the person to be identified" appears to be a reference to the offender.

${ }^{74}$ Code D, 2008 version, paragraph 1.1 .
} 
the suspect asks for one and it is practicable to hold one." ${ }^{75}$ When the Code was revised in 1995 this provision was replaced with one which imposed a duty to conduct a parade where a suspected disputed an identification and consented to a procedure being conducted. ${ }^{76}$ This reformulation did not materially affect a suspect's right to participate in an identification procedure, the right which was expressly provided in the earlier version of the Code is necessarily implied by the broader duty imposed on the police in the later version. Whether the shift in emphasis from right to duty is desirable might be measured by the effect of the changes on the quantity of material which is made available to fact-finders. It might generally be assumed that a suspect's interest in obtaining exculpatory evidence will lead him to exercise the right whenever there is a possibility that an identification procedure will result in an outcome which is useful to his defence. However, there may be various reasons why innocent suspects fail to exercise the right. Some might be unaware of the existence of a right or lack the wherewithal to assert it, while others might decline to exercise it because they perceive their position to be hopeless, or because of a refusal to engage with the criminal process out of conviction to some moral or political principle. In all but the latter case, the imposition of a duty to conduct an identification procedure may lead to an identification procedure being conducted which might not have taken place had the suspect been required to take the initiative and invoke a procedural right to participate in one.

\section{(ii) Determining When Identification Procedures Ought to be Conducted: Discretionary or Rule-governed Decision Processes?}

Both Code D and the NIJ Guide provide statements concerning the purpose of identification procedures. The adequacy of such statements assume particular significance where detailed prescription ends and officials are left to determine what course of action is to be followed. The extent of the regulation of the decision-making process which determines whether or not identification procedures are conducted is varies by jurisdiction. The NIJ Guide, for example, provides detailed guidance on the procedures that ought to be used to obtain identification evidence from an eyewitness, but has nothing to say regarding the circumstances in which those procedures should be conducted. In the absence of any directive, in deciding whether or not to conduct an identification procedure the decision-maker can be expected to refer to the function fulfilled by those

\footnotetext{
75 Paragraph 2.3, Code D (1991 version). A similar approach can be found in the relevant Australian legislation, see s3ZM(2) Crimes Act (Cth); “.... an identification parade must be held if the suspect has requested that an identification parade be held..."

${ }^{76}$ Paragraph 2.3 of the version of the Code issued in 1995 provided that "Whenever a suspect disputes an identification, an identification parade shall be held if the suspect consents..."
} 
procedures. If discretion is to be exercised satisfactorily it ought to be accompanied by a clear and comprehensive statement of the procedures' underlying purposes. ${ }^{77}$

Relatively little thought appears to have been given to this decisionmaking process. While the NIJ Guide was generally welcomed, some have suggested that, in practice, it might have little impact as the police will disregard it where it is not in their interests to follow it. ${ }^{78}$ In the context of the epistemic objective of mitigating the quantitative deficiencies in the evidence available at trial, the question of whether a procedure ought to be conducted is one of considerable importance. Is it one that ought to be left to the discretion of officials who have de facto control over the means of conducting a procedure, and whose partisan interests might be served by ensuring that none takes place? The obvious answer to this question might be 'no, there ought to be a rule determining when procedures are conducted.' However, developments in English criminal procedure illustrate the problems both of framing a suitable directive and enforcing it.

An inescapable feature of prescriptive rules is their under- and overinclusiveness. ${ }^{79}$ Rules are intended to guide action across a class of cases. They prescribe a course of action which is to be followed whenever the decision-maker is presented with some set of circumstances or facts which are thought to be characteristics of a problem which rule is designed to address. Because it will not be possible to take account of (or even envisage) the infinite variety of factual circumstances with which decision-makers will be faced, rules are necessarily probabilistic. The best that the drafter of a rule can do is to identify features which commonly signal the existence of the problem that the prescriptive content of the rule is intended to address. It was noted above that the 1995 version of Code D established a relatively simple rule, requiring the police to conduct an identification parade whenever identification was disputed and the suspect consented to a parade being held. Without ever adequately identifying the underlying purpose of this provision, the English appellate courts proceeded to modify it where it was found to be over- and under-inclusive. In $R v$ Rutherford \& Palmer ${ }^{80}$ for example, it was held that a parade should be conducted not only where identification was, in fact, disputed, but also where such a dispute could reasonably be anticipated.

\footnotetext{
77 See D. Galligan, 'Regulating Pre-trial Decisions', in I.H. Dennis (ed), Criminal Law and Justice, (1987, London; Sweet \& Maxwell); reproduced in N. Lacey, A Reader on Criminal Justice, (1994, Oxford; OUP).

${ }^{78}$ I. McKenzie, "Eyewitness Evidence: Will the United States Guide for Law Enforcement Make Any Difference?", (2003) 7 International Journal of Evidence and Proof 237.

${ }^{79}$ See generally, F. Schauer, Playing by the Rules, (1994, Oxford; Clarendon).

80 (1994) 98 Cr. App. R. 191
} 
Some of the judicial modifications to the provision were consolidated in the decision of the House of Lords in $R v$ Forbes. ${ }^{81}$ It was said that the provision which required an identification parade to be conducted was mandatory, although it should not be construed to cover all possible situations. A number of circumstances were identified in which it would not be necessary to conduct an identification parade, including those in which the witness stated that he would not be able to identify the culprit. Nor would a parade serve any useful purpose if the witness would only be able to identify the clothing worn by the culprit, or if the case was one in which the suspect was someone who was well-known to the witness. Recognition of these exceptions might be viewed as doing no more than modifying the rule. However, the Lords, while asserting that the provision imposed a mandatory obligation to conduct a parade, then went on to suggest that there may be further unspecified 'exceptional circumstances' in which it would not be necessary to conduct a parade. Presumably, determining whether those circumstances existed would be a matter for the official who was responsible for arranging a procedure, in which case he appears to possess a discretion to disregard the rule where it appears to him to provide an unsatisfactory outcome. But if the official is free to determine whether the provision applies, can it be said to be mandatory? Is it still a rule? To compound this confusion, in the version of the Code which was issued in 2003, the relatively simple rule which required a parade to be conducted whenever a suspect disputed identification and consented to appear in one, was replaced with the following provision:

"Whenever:

(i) a witness has identified a suspect or purported to identify them prior to [an identification procedure] having been held; or

(ii) there is a witness, who expresses an ability to identify the suspect, or where there is a reasonable chance of the witness being able to do so, and they have not been given an opportunity to identify the suspect in [an identification procedure];

and the suspect disputes being the person the witness claims to have seen, an identification procedure shall be held unless it is not practicable or it would serve no useful purpose in proving or disproving whether the suspect was involved in committing the offence. For example, when it is not disputed that the suspect is

${ }^{81}$ [2001] 1 All ER 686 
already well-known to the witness who claims to have seen them commit the crime." 82

Replacement of the term 'identification parade' with the generic term 'identification procedure' reflected the change in the hierarchy of procedures (video identification replacing the identification parade as the preferred procedure) which was effected in this version of the Code. Although the revised provision uses prescriptive language - "an identification procedure shall be held" - the official who contemplates the question of whether a procedure should be conducted is permitted to consider whether doing so would serve any useful purpose in "proving or disproving whether the suspect was involved in committing the offence". This is undesirable for a number of reasons. The first, a problem which we have already touched upon, is that it appears to require the police, who have partisan interests, to adopt an objective view of the value of conducting a procedure in the circumstances.

More fundamentally, it appears to be an exception which swallows the rule. It has been suggested here that one of the underlying functions of the law concerning eyewitness identification evidence is to further the objective of ensuring accurate adjudication by mitigating quantitative deficiencies in the evidence made available to the tribunal of fact. If the decision-maker is permitted to consult the background purpose of a rule, any peremptory force which it possessed is exhausted. Whether this is desirable, and whether our preference ought to be for rules or discretion in relation to this type of decision, ought to depend on which will lead to the higher incidence of satisfactory decision-making. In other words, the decision-making process ought to be determined by ascertaining whether a rule-governed or discretionary decision-making process is the more effective means of mitigating quantitative deficiencies in the evidence available at trial. Of course, a rule which requires a formal identification procedure to be conducted in every case would best achieve this end, but it would also constitute an unsustainable drain on resources. The adequacy of either process can only be properly determined in light of empirical data and although there is a substantial body of empirical research on formal identification procedures, the legal decision-making which surrounds the use of those procedures is an issue which has been largely overlooked. ${ }^{83}$

${ }^{82}$ Code D, 2003 version, paragraph 3.12.

${ }^{83}$ A. Roberts, Current Legal Issues, op. cit. n. 8. 


\section{Conclusion}

While steps have been taken to mitigate the risk of miscarriage of justice on the basis of mistaken identification in most jurisdictions over the past decade, much more could be done to ensure that identification evidence presented at trial is as complete and reliable as possible. Developments across jurisdictions are generally piecemeal and atomistic. The NIJ Guide provides detailed model procedures which have no prescriptive force. In England and Wales Code D prescribes formal identification procedures and the circumstances in which they are to be used in some detail. However, a reading of appellate hearings suggests that, more often than not, breaches of the provisions of the Code are largely inconsequential in relation to the issue of the admissibility of identification evidence. It seems that English courts place too much faith in the criminal trial as a means of establishing the reliability of such evidence. In contrast, the forensic inadequacy of the trial appears to have led to the adoption in Australia and New Zealand of statutory presumptions against the reception of such evidence where there has been a failure to conduct a formal identification procedure in the pre-trial stage of proceedings. However, the effectiveness of this approach may be undermined by the failure to prescribe, in sufficient detail, the formal identification procedures on which the reception of evidence is predicated. In those jurisdictions in which procedures are prescribed in some detail, few have adopted the sequential lineup which appears to provide the greatest degree of accuracy.

The aim of the great majority of procedural reforms has been to ensure that the eyewitness identification evidence which is presented to fact-finders is reliable. However, the problem of ensuring that the tribunal of fact is not denied an opportunity to take such evidence into account is an issue which has received very little attention. The idea that suspects might have a right to participate in identification procedures is one that does not appear to have been acknowledged in many jurisdictions. Satisfactory development of the law in this direction will require legislatures, the courts, and those responsible for administering identification procedures to have a better understanding of the normative purposes that ought to be served by the procedural law relating to eyewitness identification evidence. 